\title{
Managing Business Processes Using Soft Computing Techniques - a Literature Review
}

DOI: 10.7595/management.fon.2017.0023

\begin{abstract}
Soft computing technologies are widely used by companies for processing a large amount of data in order to make decisions, since they normally take into account both internal and external factors. Due to their tolerance of imprecision and uncertainty, Soft computing techniques (SCT) are increasingly used in solving those problems. They are characterized by the ability to adapt quickly to the changes in the environment, by stability when processing large amounts of inaccurate data and by real time responsiveness. The basic and most commonly used Soft Computing Techniques are Fuzzy logic (FL) and neural networks (NN). This paper investigated the usage of soft computing techniques in managing business processes. The main goal was to collect and review papers that describe practical and theoretical application of SCT in different business process domains, and to highlight applied models and methods. A total of 73 papers were selected based on the journals impact factor and year of publication (1965-2015), with the focus on the most recent papers. Approximately, an equal number of both Fuzzy logic and Neural Network techniques were tried to be captured and reviewed. Although this review is not final, it can be considered as a valid guide to explore the opportunities and possibilities which fuzzy logic and neural networks offer to process owners in managing their business processes. In conclusion of this paper, fields for further research were identified.
\end{abstract}

Keywords: Soft Computing, Fuzzy logic, neural networks, Business process management

JEL Classification: C45, C53, E17

\section{Introduction}

Development of computer technologies has allowed companies to process large amounts of data and real time decision making (Huang, Huang, Song \& You, 2015). Today, companies use numerous techniques which are based on the application of mathematics. Depending on the approach to the problem, there are conventional (Hard Computing) and soft computing techniques (SCT). The conventional ones are based on the principles of precision and certainty, which, besides financial resources, often require substantial time for finding a solution. On the other hand, SCTs tolerate imprecision and uncertainty (Lim \& Balas, 2013). They do not require a precisely formulated analytical model and often do not require a lot of time for computation. The term soft computing is related to the Computational intelligence, and in some cases appears as Bioinformatics because many ideas and concepts are built based on biological models. In order for one computer system to process information as a human mind, it must be flexible enough to support three characteristics: openness, robustness and real time processing. Openness represents the ability of adaptation to the changes that occur in the environment. Robustness is related to the stability and tolerance in case of processing incomplete and imprecise information. Real time processing represents the ability to react to a specific event within a reasonable time.The basic and most commonly used SCT are Fuzzy logic (FL), neural networks (NN) and probabilistic reasoning (PR). As L. Zadeh points out in his paper in 1994, FL is related to the vagueness, NN to the learning and PR to the uncertainty. The aim is to achieve traceability and robustness and find low cost solutions using the allowed tolerances for the imprecision and uncertainty (Zadeh, 1994). Soft computing techniques offer numerous possibilities for the company in the design of processes, products and services (Saridakis \& Dentsoras, 2008); they can integrate with the existing models (Zeleznikow 
\& Nolan, 2001) and give them a new dimension. The results of neural networks are based on historical data of the process (Walczak, 2001) and fuzzy logic finds its application in the treatment of linguistic variables through fuzzy numbers (Jamshidi, 2003) and in determination of rules to approximate the outputs through fuzzy sets (Lalla, Facchinetti \& Mastroleo, 2008). Also, the combined application of FL and NN is becoming more common in modelling organizational systems and predicting business results (Kar, Das \& Ghosh, 2014) as well as in the planning and allocation of the company's resources (Chang, Kuo, Wu \& Tzeng, 2015).

This paper gives an overview of the literature concerning the use of FL and NN in the field of business process management and presents the summary of the analysis of a total of 73 papers. The next part identifies segments which are characterized by the use of imprecise, uncertain and incomplete data, which is one area of SCT use. The third part gives an overview of the literature with the focus on the type of business processes, methods and variations the authors proposed to solve the problem. The fourth part contains a summary of all used papers, with an emphasis on the developed models, processes and methods. In the concluding remarks, in addition to a brief review of the analysed literature, fields for further research are identified and proposed.

\section{Problem identification}

Processes, their activities and decisions are under the influence of people whose behavior is not deterministic. Such behaviour cannot be adequately so through the crisp approach, but it is necessary to take into account the uncertainty and ambiguity whose presence is evident. Depending on the subject of management, there is more or less incomplete and inaccurate information that the system has to process. When treating process inputs, it is possible to use fuzzy numbers to display non quantified elements, and for the prediction of output values (results) of the process, it is possible to use different structures of neural networks with different learning algorithms. In terms of the process activities and their execution, it is possible to use SCT in different combinations to view, sort, and group and classify data as well as to determine the optimum values of the parameters and the process capability index. As highlighted in the introduction, these techniques can address a large number of data, and can be used to predict different types of costs, forecasting stock levels as well as support to other processes (planning, sales, design, procurement, negotiation...).

\section{Literature review}

\subsection{Neural Networks}

Neural networks offer process owners technological advantages over conventional models for decision-making and management (Hill \& Remus, 1994; Aiken \& Bsat, 1999). NN can be used in unstructured areas where a clear model does not exist or it is poorly defined (Dutta, Shekhar \& Wong, 1994). In situations in which imprecise and nonlinear data are present, NN have proven to be more reliable (Bansal, Kauffman \& Weitz, 1994; Zhang, Patuwo \& Hu, 2001) and more suitable for use (Kim, Yang \& Kim, 2008; Marques, Lacerda, Camargo \& Teixeira, 2014; Schmidhuber, 2015) compared to the results of statistical models (Joseph, Larrain, Turner, 2014). NN can simultaneously handle multiple types of data and therefore can be used in risk assessment and decision-making (Calderon \& Cheh, 2002). Seasonality and variations in the trend of certain data are present in planning and decision-making of almost all business processes and their modelling can also be achieved by using NN (Zhang \& Qi, 2005). Authors (Smith \& Gupta, 2000) explained the three most popular models of NN for solving the above problems in business processes - feedforward, Hopfield and self-organizing. They emphasize the similarity of these models with traditional statistical and operational research techniques, and as the basic difference point out that NN do not make assumptions regarding the statistical distribution or characteristics of the treated data, which is why in practical situations they are more applicable. Many processes in companies are of such a nature that it is not possible to carry out testing and experimentation using conventional methods without compromising their functioning. The advantage of $\mathrm{NN}$ is that they can simulate the results without interrupting or disrupting the regular functioning of the process and still take into account the nonlinear relationship between the parameters and results. The authors (Ansuj, Camargo \& Radharamanan, 1996), for predicting sales process, compare two models - neural networks with backpropagation learning algorithm and ARIMA model for time series analysis. Based on gained results, the authors conclude that neural networks are more accurate. Concerning a similar problem, (Agrawal \& Schorling, 1996) compare forecasting results of sales process for the three brands using NN and Multinomial logistic regression, where NN also provide more accurate predictions. (Kuo \& Xue, 1998a) developed a system for predicting sales results that considers quantitative and non-quantitative factors. For learning on data from previous periods and predicting results for the period period to come, the authors use feedforward NN with error-backpropagation learning algorithm. For special activities that can affect sales results (e.g., promotion), 
they upgrade the model with fuzzy logic. Based on the result comparison of the proposed model (FNN) and conventional statistics, the authors conclude that FNN results are more accurate. After that, the same authors (Kuo \& Xue, 1998b) expand the existing FNN model with fuzzy IF-THEN rules for pater recognition in prediction. Considering different internal and external factors, many other authors use NN for forecasting sales process in order to better plan capacity, production and other activities (Luxhøj, Riis \& Stensballe, 1996; Kuo, 2001; Thomassey \& Happiette, 2007; Sun, Choi, Au \& Yu, 2008; Wong \& Guo, 2010). (Corstena \& May, 1996) and (Feng, Li, Cen \& Huang, 2003) point out the possibility of using NN for managing the production process. When it comes to the production planning (Cavalieri,Maccarrone \& Pinto, 2004), for modelling cause and effect relation between design solutions and costs, traditional statistical model and NN are combined. Based on the obtained results, NN are highlighted as a more valid option. (Moosmayer,Chong, Liu \& Schuppar, 2013) examined the impact of annual price, the desired price and the initial offer as factors in negotiation and procurement process. To bypass nonlinear decisions that affect the process of negotiations and to determine factors with the greatest impact on the mentioned process, they used NN and compared results with the one obtained by regression analysis. For predicting demand in the supply chain (Carbonneau, Laframboise \& Vahidov, 2008) use NN and (Aburto \& Weber, 2007) propose combination of NN with auto-regressive analysis. (Mansur \& Kuncoro 2012), for predicting the level of product stock that needs to be kept in the retail store, suggest the use of neural networks with backpropagation learning algorithm. The results which NN provide to the process owners in the form of prediction are subject to uncertainty and are used together with a certain level of error. For bridging and reducing those errors (Mazloumi, Rose, Currie \& Moridpour, 2011) grouped the obtained results into intervals, which opens space for further process planning. In addition to forecasts, NN can be used for determination the impact of input parameters on the process and verification of their optimal values (Co, 2007; Zobel \& Cook 2011). Similarly, (Tejedor, Elola \& Tejedor, 2008) use NN for examination and determination of KPIs correlation in Balanced Scorecard model on the model in the case of processes in the health sector and suggest the use of the developed model in other sectors. It is important to point out that the trained network can be used in the opposite direction. To optimize the process, it is possible to enter the desired value of results in the already trained neural network in order to obtain optimal values of process parameters (Chiang, Su, Li \& Huang, 2001).

\subsection{Fuzzy logic}

A majority of the problems in the economy and organizational sciences often do not have a clearly defined structure, which is the main reason for the constant development of FL in order to overcome those problems (Zadeh, 1965; Skala, 1978). The main contribution of FL is reflected in the treatment of linguistic variables, the use of fuzzy rules and fuzzy graphs (Sugeno \& Tanaka, 1991). By using these concepts and methods, FL represents a powerful tool in the decision making process in situations where it is not possible to accurately determine all the factors (Grabisich, 1996; Narukawa \& Torra, 2007; Zhu \& Xu, 2014) and to display the company's results based on qualitative indicators (Muñoz, Rivera \& Moneva, 2008). A very important field of fuzzy logic application refers to the determination of process efficiency (Kao \& Liu, 2011; Lozano, 2014) and capability (Kaya \& Kahraman, 2011; Wu \& Liao, 2014). (Parchami \& Mashinchi, 2007) in their work use many intervals to calculate the process capability index via triangular fuzzy numbers. (Wu, 2009) points out that some of the continual variables which are used for the calculation of the process capability index are not precise numbers and also propose the use of triangular fuzzy numbers for dealing with that problem. Often, there are situations where quality characteristics of certain processes are unclear, incomplete or linguistically defined. For monitoring stability and capability of such processes with control charts, the use of fuzzy logic is inevitable (Cheng, 2005; Faraz \& Shapiro, 2010). To treat the input-output relationship of correlated processes within the supply chain, many authors identify areas and segments where uncertainty is present and suggest the use of fuzzy logic to overcome it (Ko, Tiwari \& Mehnen, 2010). (Peidro,Mula, Poler \& Verdegay, 2009) propose the application of fuzzy logic and IF-THEN rules for treating sources of uncertainty when determining supply and demand in the supply chain in automotive industry. (Campuzano, Mula \& Peidro, 2010) developed a model for production planning that treats demand and orders through fuzzy numbers. For hidden quality costs estimation, (Martinez \& Selles, 2015) use fuzzy numbers and sets. For selecting the supplier (Davis,Shipley \& Stading, 2015) suggest a quantification of certain criteria using fuzzy numbers. A second most important field in which fuzzy logic is increasingly finding its application is QFD (Quality Function Deployment). QFD represents the tool for translating customer requirements into the appropriate requirements of the company. As this method maps the customer requirements and translates them to project tasks, it opens up numerous possibilities for the use of fuzzy logic and numbers. (Chen \& Ko, 2008) propose a fuzzy nonlinear model for the determination of the requirements fulfilment level in the second iteration of building the House of Quality. (Liu, 2009) expands fuzzy QFD approach from planning to the design of the product, and (Hsu \& Lin, 2006) use fuzzy numbers to assess the value and intensity of customers. Many authors used fuzzy numbers to upgrade existing models for business process management. (Volkner \& Werners, 2002) upgrade the existing system GEPSIS for planning business processes with 
a special component which treats language uncertainty of some process elements. They apply and test the new system in the case of general process "order taking", and use fuzzy numbers for four process attributes (Waiting time on the reception; Time in system; Processing priority; Delivery time;). Authors (Torabi,Ebadian \& Tanha, 2010) upgrade the existing framework for production planning with fuzzy logic to treat the problem of inaccurate data and unclear restrictions. Adding necessary flexibility to an existing model, they enable the creation of a more reliable production plan. (Yu \& Tzeng, 2006) improve the existing ANP/AHP model for treating MCDM problem with decision maps which function based on FL. For risk assessment (Kumru \& Kumru, 2013) join to widely use FMEA fuzzy segment for bridging the irregularities when determining a Risk priority number. (Tseng, 2010) uses FL to evaluate uncertainty of $22 \mathrm{KPIs}$ in four Balanced Scorecard perspectives, and (Jassbi, Mohamadnejad \& Nasrollahzadeh, 2011) use FL to model their relationship in the strategic map. Similarly, (El-Mongy, Hamouda, Nounou \& Wahdan, 2013) join both FL and NN to the BSC model for predicting results of the KPIs in BSC perspectives.

\section{Results}

This part gives the summary of the analysis results. Papers are divided into three groups -Fuzzy Logic, Neural Networks, and Neural Networks \& Fuzzy Logic. Approximately, an equal share of both FL (44\%) and NN (45\%)papers were reviewed, with the significant amount of papers that cover the combination of techniques $(12 \%)$. The following table represents the models developed and used to support business processes and their "owners". For each of the models, numbers of analysed papers are given.

Table 1: Used models in analysed papers

\begin{tabular}{|c|c|c|}
\hline & Models & \# \\
\hline \multirow{11}{*}{$\begin{array}{l}\frac{0}{\mathrm{O}} \\
\frac{\mathrm{O}}{\mathrm{N}} \\
\stackrel{\mathrm{N}}{\mathbf{V}}\end{array}$} & Control charts (Cheng, 2005), (Faraz \& Shapiro, 2010), (Kaya \& Kahraman, 2011). & 3 \\
\hline & Data Envelopment Analysis (Kao \& Liu, 2011), (Lozano, 2014). & 2 \\
\hline & Decision support (Zeleznikow \& Nolan, 2001), (Yu \& Tzeng, 2006). & 2 \\
\hline & Inference Engine (El-Mongy et all., 2013). & 1 \\
\hline & Linear programming (Torabi et all., 2010), (Zhu \& Xu, 2014) \& nonlinear model (Chen \& Ko, 2008). & 3 \\
\hline & $\begin{array}{l}\text { Logic-based default model (Lalla et all., 2008), (Grabisich, 1996), (Narukawa \& Torra, 2007), (Muñoz et } \\
\text { all., 2008), (Campuzano et all., 2010), (Tseng, 2010), (Skala, 1978). }\end{array}$ & 7 \\
\hline & Probabilistic sets (Wu \& Liao, 2014), (Davis et all., 2015). & 2 \\
\hline & Specific models - DEMATEL (Jassbi et all., 2011); FMEA (Kumru \& Kumru, 2013); GEPSIS (Volkner \& & \\
\hline & $\begin{array}{l}\text { Werners, 2002); QFD (Hsu \& Lin, 2006), (Liu, 2009), (Martinez \& Selles, 2015); Takagi \& Sugeno (Sugeno } \\
\text { \& Tanaka, 1991); }\end{array}$ & 7 \\
\hline & Literature review of application (Ko et all., 2010). & 1 \\
\hline & Triangular numbers (Parchami \& Mashinchi, 2007), (Wu, 2009), (Peidro et all., 2009). & 3 \\
\hline \multirow{4}{*}{ 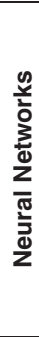 } & $\begin{array}{l}\text { Feedforward \& back propag. learning algorithm \& multiple layers, (Bansal et all., 1994), (Dutta et all., } \\
\text { 1994), (Hill \& Remus, 1994), (Corstena \& May, 1996), (Agrawal \& Schorling, 1996), (Ansuj et all., 1996), } \\
\text { (Kuo \& Xue, 1998a), (Kuo \& Xue, 1998b), (Walczak, 2001), (Kuo, 2001), (Zhang et all., 2001), (Chiang et } \\
\text { all., 2001), (Calderon \& Cheh, 2002), (Feng et all., 2003), (Cavalieri et all., 2004), (Zhang \& Qi, 2005), (Co, } \\
\text { 2007), (Aburto \& Weber, 2007), (Carbonneau et all., 2008), (Kim et all., 2008), (Sun et all., 2008), (Tejedor } \\
\text { et all., 2008), (Wong \& Guo, 2010), (Zobel \& Cook 2011), (Mazloumi et all., 2011), (Mansur \& Kuncoro } \\
\text { 2012), (Moosmayer et all., 2013), (Marques et all., 2014). }\end{array}$ & 28 \\
\hline & Feedforward \& multiple learning algorithm \& multiple layers (Aiken \& Bsat, 1999), (Schmidhuber, 2015). & 2 \\
\hline & Literature review of application (Smith \& Gupta, 2000). & 1 \\
\hline & $\begin{array}{l}\text { Specific model - Hybrid (Luxhøj et all., 1996); Levenberg-Marquardt (Joseph et all., 2014); Probabilistic } \\
\text { nets (Thomassey \& Happiette, 2007). }\end{array}$ & 3 \\
\hline \multirow{3}{*}{$\begin{array}{l}\overrightarrow{1} \\
\propto \\
Z \\
Z\end{array}$} & Feedforward \& back propag. learning algorithm \& multiple layers (Zadeh, 1965), (Zadeh, 1994). & 2 \\
\hline & $\begin{array}{l}\text { Combined Neural Network and Fuzzy logic model (Jamshidi, 2003), (Kar et all., 2014), (Chang et all., } \\
\text { 2015). }\end{array}$ & 3 \\
\hline & Literature review of application (Saridakis \& Dentsoras, 2008), (Lim \& Balas, 2013), (Huang et all., 2015). & 3 \\
\hline
\end{tabular}

Based on the above table, it can be seen that the majority of the analysed models (28) are related to the feedforward neural networks with multiple layers and back propagation learning algorithm. When it comes to the analysed fuzzy models, both default model (7) and specific models (7) are equally used in the business processes management. The table below shows the processes on which SCT and models are applied Fuzzy logic (g1), neural networks (g2) and fuzzy logic \& neural networks combinations (g3). 
Table 2: Business Processes covered

\begin{tabular}{|c|c|c|c|}
\hline Process & g1 & g2 & g3 \\
\hline $\begin{array}{l}\text { Manufacturing (Hill \& Remus, 1994), (Corstena \& May, 1996), (Chiang et all., 2001), (Volkner \& } \\
\text { Werners, 2002), (Jamshidi, 2003), (Feng et all., 2003), (Cheng, 2005), (Co, 2007), (Parchami \& } \\
\text { Mashinchi, 2007), (Wu, 2009), (Faraz \& Shapiro, 2010), (Torabi et all., 2010), (Zobel \& Cook 2011), } \\
\text { (Kao \& Liu, 2011), (Kaya \& Kahraman, 2011), (Kar et all., 2014), (Huang et all., 2015), (Martinez \& } \\
\text { Selles, 2015). }\end{array}$ & 9 & 6 & 3 \\
\hline $\begin{array}{l}\text { New product development (Cavalieri et all., 2004), (Saridakis \& Dentsoras, 2008), (Chen \& Ko, } \\
\text { 2008), (Liu, 2009). }\end{array}$ & 2 & 1 & 1 \\
\hline $\begin{array}{l}\text { Overall theoretical and practical application (Zadeh, 1965), (Skala, 1978), (Zadeh, 1994), } \\
\text { (Grabisich, 1996), (Lim \& Balas, 2013), (Schmidhuber, 2015). }\end{array}$ & 2 & 1 & 3 \\
\hline $\begin{array}{l}\text { Procurement (Yu \& Tzeng, 2006), (Moosmayer et all., 2013), (Kumru \& Kumru, 2013), (Wu \& Liao, } \\
\text { 2014), (Davis et all., 2015). }\end{array}$ & 4 & 1 & 0 \\
\hline $\begin{array}{l}\text { Performance measurement (Zeleznikow \& Nolan, 2001), (Lalla et all., 2008), (Muñoz et all., 2008), } \\
\text { (El-Mongy et all., 2013), (Lozano, 2014). }\end{array}$ & 5 & 0 & 0 \\
\hline $\begin{array}{l}\text { Strategy management (Sugeno \& Tanaka, 1991), (Calderon \& Cheh, 2002), (Narukawa \& Torra, } \\
\text { 2007), (Kim et all., 2008), (Tejedor et all., 2008), (Tseng, 2010), (Jassbi et all., 2011), (Zhu \& Xu, } \\
\text { 2014), (Chang et all., 2015). }\end{array}$ & 5 & 3 & 1 \\
\hline $\begin{array}{l}\text { Sales (Luxhøj et all., 1996), (Agrawal \& Schorling, 1996), (Ansuj et all., 1996), (Kuo \& Xue, 1998a), } \\
\text { (Kuo \& Xue, 1998b), (Kuo, 2001), (Zhang et all., 2001), (Zhang \& Qi, 2005), (Hsu \& Lin, 2006), } \\
\text { (Thomassey \& Happiette, 2007), (Sun et all., 2008), (Wong \& Guo, 2010), (Marques et all., 2014), } \\
\text { (Joseph et all., 2014). }\end{array}$ & 1 & 13 & 0 \\
\hline $\begin{array}{l}\text { Supply chain (Walczak, 2001), (Aburto \& Weber, 2007), (Carbonneau et all., 2008), (Peidro et all., } \\
\text { 2009), (Ko et all., 2010), (Campuzano et all., 2010), (Mazloumi et all., 2011), (Mansur \& Kuncoro } \\
\text { 2012). }\end{array}$ & 3 & 5 & 0 \\
\hline Finance (Bansal et all., 1994), (Dutta et all., 1994), (Aiken \& Bsat, 1999), (Smith \& Gupta, 2000). & 0 & 4 & 0 \\
\hline
\end{tabular}

Table 2 indicates that SCT are used in various process domains, and especially in manufacturing and sales. The following table represents the methods applied in business processes management, also divided per above groups (g1, g2, g3).

Table 3: Used methods in analysed papers

\begin{tabular}{|c|c|c|c|}
\hline Method & g1 & g2 & g3 \\
\hline $\begin{array}{l}\text { Classification (Dutta et all., 1994), (Walczak, 2001), (Zeleznikow \& Nolan, 2001), (Chiang et all., } \\
\text { 2001), (Feng et all., 2003), (Thomassey \& Happiette, 2007), (Tejedor et all., 2008), (Huang et all., } \\
\text { 2015), (Chang et all., 2015). }\end{array}$ & 1 & 6 & 2 \\
\hline $\begin{array}{l}\text { Estimation (Parchami \& Mashinchi, 2007), (Chen \& Ko, 2008), (Wu, 2009), (Peidro et all., 2009), (Liu, } \\
\text { 2009), (Faraz \& Shapiro, 2010), (Torabi et all., 2010), (Kaya \& Kahraman, 2011), (Kumru \& Kumru, } \\
\text { 2013), (Zhu \& Xu, 2014), (Wu \& Liao, 2014), (Lozano, 2014), (Martinez \& Selles, 2015). }\end{array}$ & 13 & 0 & 0 \\
\hline $\begin{array}{l}\text { Evaluation (Skala, 1978), (Grabisich, 1996), (Volkner \& Werners, 2002), (Cheng, 2005), (Yu \& Tzeng, } \\
\text { 2006), (Hsu \& Lin, 2006), (Narukawa \& Torra, 2007), (Lalla et all., 2008), (Muñoz et all., 2008), } \\
\text { (Tseng, 2010), (Jassbi et all., 2011), (Kao \& Liu, 2011), (Marques et all., 2014), (Davis et all., 2015). }\end{array}$ & 13 & 1 & 0 \\
\hline $\begin{array}{l}\text { Forecasting (Sugeno \& Tanaka, 1991), (Bansal et all., 1994), (Hill \& Remus, 1994), (Luxhøj et all., } \\
\text { 1996), (Corstena \& May, 1996), (Agrawal \& Schorling, 1996), (Ansuj et all., 1996), (Kuo \& Xue, } \\
\text { 1998a), (Kuo \& Xue, 1998b), (Aiken \& Bsat, 1999), (Kuo, 2001), (Zhang et all., 2001), (Calderon \& } \\
\text { Cheh, 2002), (Cavalieri et all., 2004), (Zhang \& Qi, 2005), (Co, 2007), (Aburto \& Weber, 2007), } \\
\text { (Carbonneau et all., 2008), (Kim et all., 2008), (Sun et all., 2008), (Wong \& Guo, 2010), (Campuzano } \\
\text { et all., 2010), (Zobel \& Cook 2011), (Mazloumi et all., 2011), (Mansur \& Kuncoro 2012), (Moosmayer } \\
\text { et all., 2013), (El-Mongy et all., 2013), (Joseph et all., 2014). }\end{array}$ & 3 & 25 & 0 \\
\hline $\begin{array}{l}\text { Multiple methods analyzed (Zadeh, 1965), (Zadeh, 1994), (Smith \& Gupta, 2000), (Jamshidi, 2003), } \\
\text { (Saridakis \& Dentsoras, 2008), (Ko et all., 2010), (Lim \& Balas, 2013), (Kar et all., 2014), } \\
\text { (Schmidhuber, 2015). }\end{array}$ & 1 & 2 & 6 \\
\hline
\end{tabular}

Table 3 indicates a significant usage of both evaluation and estimation methods for fuzzy logic, and in case of neural networks, forecasting method is mostly applied. From a total of 73 analysed papers, the largest number is published in the journal Fuzzy Sets and Systems (15), in the Applied Soft Computing (6) and Decision Support Systems (6) and Expert Systems with Applications (5) journals. The variety of journals in which papers were published indicate that the application of SCT in the field of business process management has been recognized by the wider professional community. 


\section{Conslusion}

The basic idea underlying the SCT is related to the modelling of the behavior of the human mind. Unlike conventional ones, these "soft" techniques tolerate imprecision, uncertainty and approximate values. Based on the above conducted analysis of the relevant literature, the use of SCT in various segments of business process management is presented in this paper. A total of 73 papers were analysed and divided into three groups. Papers which provide a start of the development of SCT (8), papers relating to the application of NN (34) and papers relating to the application of FL (31). Taking into account the number and variety of journals, models and methods applied, it can be concluded that FL and NN are widely present as a tool for solving problems in business processes. Further research can be referring to the definition of a model that will consolidate and use different combinations of existing, improved and new methods and variations of SCT (neural networks and fuzzy logic) to overcome the problems of imprecision and uncertainty in specific segments of business processes management.

\section{REFERENCES}

[1] Aburto, L., \&Weber, R., (2007). Improved supply chain management based on hybrid demand forecasts. Applied Soft Computing,(7), 136-144. DOI: 10.1016/j.asoc.2005.06.001

[2] Agrawal, D., \&Schorling, C., (1996). Market Share Forecasting: An empirical comparison of ANN and Multinomial Logit Model. Journal of Retailing, (72), 383-407.

[3] Aiken, M., \&Bsat, M., (1999). Forecasting market trends with Neural Networks. Information Systems Management, 42-48.

[4] Ansuj, A.P., Camargo, M.E., Radharamanan, R., \&Petty, D.G., (1996). Sales forecasting using time series and neural networks. Computers \& Industrial Engineering, 31(1-2), 421-424.

[5] Bansal, A., Kauffman, R.J., \&Weitz R.R., (1994). Comparing the Modelling Performance of Regression and Neural Networks as Data Quality Varies: A Business Value Approach. Journal of Management Information System, 10(1), 11-32.

[6] Calderon, T.G., \&Cheh, J.J., (2002). A roadmap for future neural networks research in auditing and risk assessment. International Journal of Accounting Information Systems, 3, 203-236.

[7] Campuzano, F., Mula, J., \&Peidro, D., (2010).Fuzzy estimations and system dynamics for improving supply chains. Fuzzy Sets and Systems, 161, 1530-1542. DOI: 10.1016/j.fss.2009.12.002

[8] Carbonneau, R., Laframboise, K., \&Vahidov, R., (2008). Application of machine learning techniques for supply chain demand forecasting. European Journal of Operational Research, 184, 1140-1154. DOI: 10.1016/j.ejor.2006.12.004

[9] Cavalieri, S., Maccarrone, P., \&Pinto, R., (2004). Parametric vs. NN models for the estimation of production costs - A case study in the automotive industry. International Journal of Production Economics, 91, 165-177. DOI: 10.1016/j.ijpe.2003.08.005

[10] Chang, B., Kuo, C., Wu, C-H., \&Tzeng G-H., (2015). Using Fuzzy Analytic Network Process to assess the risks in enterprise resource planning system implementation. Applied Soft Computing, 28, 196-207. DOI: https://doi.org/10.1016/j.asoc.2014.11.025

[11] Chen, L-H., \&Ko, W-C., (2008). A fuzzy nonlinear model for quality function deployment considering Kano's concept. Mathematical and Computer Modelling, 48, 581-593. DOI: 10.1016/j.mcm.2007.06.029

[12] Cheng, C-B., (2005). Fuzzy process control: construction of control charts with fuzzy numbers. Fuzzy Sets and Systems, 154, 287-303. DOI: 10.1016/j.fss.2005.03.002

[13] Chiang, T.-L., Su, C.-T., Li, T.-S., \&Huang, R.C.C., (2001). Improvement of Process Capability through Neural Networks and Robust Design: A Case Study. Quality Engineering, 14(2), 313-318.

[14] Co, H. C., (2007). Confirmation testing of the Taguchi methods by artificial neural-networks simulation. International Journal of Production Research, 1-15. DOI: 10.1080/00207540701213502

[15] Corstena, H., \&May, C., (1996). Artificial neural networks for supporting production planning and control. Technovation, 16(2), 67-76.

[16] Davis, J., Shipley, M. F., \&Stading, G., (2015). A Fuzzy Supplier Selection Application Using Large Survey Datasets of Delivery Performance. Advances in Fuzzy Systems, Vol. 2015. DOI: http://dx.doi.org/10.1155/2015/841485

[17] Dutta, S., Shekhar, S., \&Wong, W.Y., (1994). Decision support in non-conservative domains: Generalization with neural networks. Decision Support Systems, 11, 527-544. 
[18] El-Mongy, A.M.A., Hamouda, A.el-D., Nounou, N., \&Wahdan, A.I-M., A., (2013). Design of Prediction System for Key Performance Indicators in Balanced Scorecard. International Journal of Computer Applications (0975 - 8887),72(8), 10-14.

[19] Faraz, A., \&Shapiro, A.F., (2010). An application of fuzzy random variables to control charts. Fuzzy Sets and Systems,(161), 2684-2694. DOI: 10.1016/j.fss.2010.05.004

[20] Feng, S., Li, L., Cen, L., \&Huang, J., (2003). Using MLP networks to design a production scheduling system. Computers \& Operations Research, 30(6), 821-832.

[21] Grabisch, M., (1996). The application of fuzzy integrals in multicriteria decision making. European Journal of Operational Research, 89, 445-456.

[22] Hill, T., \&Remus, W., (1994). Neural network models for intelligent support of managerial decision making. Decision Support Systems, 11, 449-459.

[23] Hsu, T-H., \&Lin, L-Z., (2006). QFD with Fuzzy and Entropy Weight for Evaluating Retail Customer Values. Total Quality Management, 17(7), 935-958. DOI: 10.1080=14783360600598223

[24] Huang, G., Huang, G-B., Song, S., \&You, K., (2015). Trends in extreme learning machines: A review. Neural Networks, 61, 32-48.

DOI: http://dx.doi.org/10.1016/j.neunet.2014.10.001

[25] Jamshidi, M., (2003). Tools for Intelligent Control: Fuzzy Controllers, Neural Networks and Genetic Algorithms. Philosophical Transactions: Mathematical, Physical and Engineering Sciences. Information, Knowledge and Technology, 361(1809), 1781-1808.

[26] Jassbi, J., Mohamadnejad, F., \&Nasrollahzadeh, H., (2011). A Fuzzy DEMATEL framework for modeling cause and effect relationships of strategy map. Expert Systems with Applications, 38, 5967-5973. DOI:10.1016/j.eswa.2010.11.026

[27] Joseph, A., Larrain, M., \&Turner, C., (2014). The Treasury Bill Rate, the Great Recession, and Neural Networks estimates of Real Business Sales. Procedia Computer Science, 36, 227-233. DOI: 10.1016/j.procs.2014.09.084

[28] Kar, S., Das, S., \&Ghosh, P.K., (2014). Applications of neuro fuzzy systems: A brief review and future outline. Applied Soft Computing, 15, 234-259. DOI: http://dx.doi.org/10.1016/j.asoc.2013.10.014

[29] Kao, C., \&Liu, S-T., (2011). Efficiencies of two-stage systems with fuzzy data. Fuzzy Sets and Systems, 176(1), 20-35. DOI: 10.1016/j.fss.2011.03.003

[30] Kaya, I., \&Kahraman, C., (2011). Process capability analyses based on fuzzy measurements and fuzzy control charts. Expert Systems with Applications, 38(4), 3172-3184. DOI: 10.1016/j.eswa.2010.09.004

[31] Kim, C.N., Yang, K.H., \&Kim, J., (2008). Human decision-making behavior and modelling effects. Decision Support Systems, 45, 517-527. DOI: 10.1016/j.dss.2007.06.011

[32] Ko, M., Tiwari, A., \&Mehnen, J., (2010). A review of Soft Computing applications in supply chain management. Applied Soft Computing, 10, 661-674.DOI: 10.1016/j.asoc.2009.09.004

[33] Kuo, R.J., \&Xue, K.C., (1998a). An intelligent sales forecasting system through integration of artificial neural network and fuzzy neural network. Computers in Industry, 37, 1-15.

[34] Kuo, R.J., \&Xue, K.C., (1998b). A decision support system for sales forecasting through fuzzy neural networks with asymmetric fuzzy weights. Decision Support Systems, 24, 105-126.

[35] Kuo, R.J., (2001). A sales forecasting system based on fuzzy neural network with initial weights generated by genetic algorithm. European Journal of Operational Research, 129(3), 496-517.

[36] Kumru, M., \&Kumru, P.Y., (2013). Fuzzy FMEA application to improve purchasing process in a public hospital. Applied Soft Computing, 13, 721-733. DOI: http://dx.doi.org/10.1016/j.asoc.2012.08.007

[37] Lalla, M., Facchinetti, G., \&Mastroleo, G., (2008). Vagueness evaluation of the crisp output in a fuzzy inference system. Fuzzy Sets and Systems, 159, 3297-3312.DOI: 10.1016/j.fss.2008.03.002

[38] Lim, C.P., Balas, V.E., \&Do, Q., (2013). Special issue recent advances in soft computing: Theories and applications. Journal of Intelligent \& Fuzzy Systems, 24, 415-416. DOI: 10.3233/IFS-2012-0562

[39] Liu, H-T., (2009). The extension of fuzzy QFD: From product planning to part deployment. Expert Systems with Applications, 36, 11131-11144. DOI: 10.1016/j.eswa.2009.02.070

[40] Lozano, S., (2014). Process efficiency of two-stage systems with fuzzy data. Fuzzy Sets and Systems, 243, 36-49. DOI: http://dx.doi.org/10.1016/j.fss.2013.05.012

[41] Luxhøj, J.T., Riis, J.O., \&Stensballe, B., (1996). A hybrid econometric - neural network modelling approach for sales forecasting. International Journal of Production Economics, 43(2-3), 175-192.

[42] Mansur, A., \&Kuncoro, T., (2012). Product Inventory Predictions at Small Medium Enterprise Using Market Basket Analysis Approach-Neural Networks. Procedia Economics and Finance. International Conference on Small and Medium Enterprises Development with a Theme "Innovation and Sustainability in SME Development” (ICSMED), 4, 312-320. DOI: 10.1016/S2212-5671(12)00346-2 
[43] Marques, A., Lacerda, D.P., Camargo, L.F.R., \&Teixeira, R., (2014). Exploring the relationship between marketing and operations: Neural network analysis of marketing decision impacts on delivery performance. International Journal of Production Economics, 153, 178-190.

DOI: http://dx.doi.org/10.1016/j.ijpe.2014.02.020

[44] Martinez, J.M.B., \&Selles, M.E.S., (2015). A fuzzy quality cost estimation method. Fuzzy Sets and Systems, 266, 157-170. DOI: http://dx.doi.org/10.1016/j.fss.2014.12.014

[45] Mazloumi, E., Rose, G., Currie, G., \&Moridpour, S., (2011). Prediction intervals to account for uncertainties in neural network predictions: Methodology and application in bus travel time prediction. Engineering Applications of Artificial Intelligence, 24, 534-542. DOI: doi:10.1016/j.engappai.2010.11.004

[46] Moosmayer, D.C., Chong, A.Y-L., Liu, M.J., \&Schuppar, B., (2013). A neural network approach to predicting price negotiation outcomes in business-to-business contexts. Expert Systems with applications, 40, 3028-3035. DOI: http://dx.doi.org/10.1016/j.eswa.2012.12.018

[47] Muñoz, M.J., Rivera, J.M., \&Moneva, J.M., (2008). Evaluating sustainability in organisations with a fuzzy logic approach. Industrial Management \& Data Systems, 108(6), 829-841.

DOI: http://dx.doi.org/10.1108/02635570810884030

[48] Narukawa, Y., \&Torra, V., (2007). Fuzzy measures and integrals in evaluation of strategies. Information Sciences, 177, 4686-4695. DOI: 10.1016/j.ins.2007.05.010

[49] Parchami, A., \&Mashinchi, M., (2007). Fuzzy estimation for process capability indices. Information Sciences, 177, 1452-1462. DOI: 10.1016/j.ins.2006.08.016

[50] Peidro, D., Mula, J., Poler, R., \&Verdegay, J-L., (2009). Fuzzy optimization for supply chain planning under supply, demand and process uncertainties. Fuzzy Sets and Systems, 160, 2640-2657. DOI: 10.1016/j.fss.2009.02.021

[51] Saridakis, K.M., \&Dentsoras, A.J., (2008). Soft computing in engineering design - A review. Advanced Engineering Informatics, 22, 202-221. DOI:10.1016/j.aei.2007.10.001

[52] Schmidhuber, J., (2015). Deep learning in neural networks: An overview. Neural Networks, 61, 85-117. DOI: http://dx.doi.org/10.1016/j.neunet.2014.09.003

[53] Skala, H.J., (1978). On many-valued logics, fuzzy sets, fuzzy logics and their applications. Fuzzy Sets and Systems, 1, 129-149.

[54] Smith, K.A., \&Gupta, J.N.D., (2000). Neural networks in business: techniques and applications for the operations researcher. Computers \& Operations Research, 27, 1023-1044.

[55] Sugeno, M., \&Tanaka, K., (1991). Successive identification of a fuzzy model and its applications to prediction of a complex system. Fuzzy Sets and Systems, 42, 315-334.

[56] Sun, Z-L., Choi, T-M., Au, K-F., \&Yu, Y., (2008). Sales forecasting using extreme learning machine with applications in fashion retailing. Decision Support Systems, 46, 411-419. DOI: 10.1016/j.dss.2008.07.009

[57] Tejedor, J.P., Elola, L.N., \&Tejedor, A.C., (2008). The application of neural networks in the study of the influence of temporality on strategy map indicators in a Spanish hospital. Total Quality Management, 19(6), 643-659. DOI:10.1080/14783360802024119

[58] Thomassey, S., \&Happiette, M., (2007). A neural clustering and classification system for sales forecasting of new apparel items. Applied Soft Computing, 7, 1177-1187.

DOI: 10.1016/j.asoc.2006.01.005

[59] Torabi, S.A., Ebadian, M., \&Tanha, R., (2010). Fuzzy hierarchical production planning (with a case study). Fuzzy Sets and Systems, 161, 1511-1529. DOI: 10.1016/j.fss.2009.11.006

[60] Tseng, M-L., (2010). Implementation and performance evaluation using the fuzzy network balanced scorecard. Computers \& Education, 55, 188-201. DOI: 10.1016/j.compedu.2010.01.004

[61] Volkner, P., \&Werners, B., (2002). A simulation based decision support system for business process planning. Fuzzy Sets and Systems, 125, 275-287.

[62] Walczak S., (2001). Neural networks as a tool for developing and validating business heuristics. Expert Systems with Applications, 21(1), 31-36.

[63] Wong, W.K., \&Guo, Z.X., (2010). A hybrid intelligent model for medium-term sales forecasting in fashion retail supply chains using extreme learning machines and harmony search algorithm. International Journal of Production Economics, 128, 614-624. DOI: 10.1016/j.ijpe.2010.07.008

[64] Wu, C-W., (2009). Decision-making in testing process performance with fuzzy data. European Journal of Operational Research, 193, 499-509. DOI: 10.1016/j.ejor.2007.11.044

[65] Wu, C-W., \&Liao, M-Y., (2014). Fuzzy nonlinear programming approach for evaluating and ranking process yields with imprecise data. Fuzzy Sets and Systems, 246, 142-155. DOI: 10.1016/j.fss.2013.10.014

[66] Yu, R., \&Tzeng, G.-H., (2006). A soft computing method for multi-criteria decision making with dependence and feedback. Applied Mathematics and Computation, 180, 63-75.

DOI: 10.1016/j.amc.2005.11.163

[67] Zadeh L.A., (1965). Fuzzy Sets. Information and Control,(8), 338-353.

[68] Zadeh L. A., (1994). Fuzzy Logic, Neural Networks, and Soft Computing. Communications of the $A C M, 37(3)$. 
[69] Zeleznikow, J., \&Nolan, J.R., (2001). Using soft computing to build real world intelligent decision support systems in uncertain domains. Decision Support Systems,(31), 263-285.

[70] Zhang, G.P., Patuwo, B.E., \&Hu, M.Y., (2001). A simulation study of artificial neural networks for nonlinear time-series forecasting. Computers \& Operations Research, 28, 381-396.

[71] Zhang, G.P., \&Qi, M., (2005). Neural network forecasting for seasonal and trend time series. European Journal of Operational Research, 160(2), 501-514. DOI: 10.1016/j.ejor.2003.08.037

[72] Zhu, B., \&Xu, Z., (2014). A fuzzy linear programming method for group decision making with additive reciprocal fuzzy preference relations. Fuzzy Sets and Systems,246, 19-33. DOI: http://dx.doi.org/10.1016/j.fss.2014.01.001

[73] Zobel, C.W., \&Cook, D.F., (2011). Evaluation of Neural Network variable influence measures for process control. Engineering Applications of Artificial Intelligence, 24, 803-812. DOI: 10.1016/j.engappai.2011.03.001

Received: 2017-07-18

Accepted: 2017-10-18

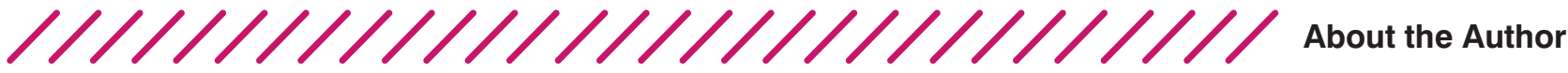

\section{Nikola Vojtek \\ University of Belgrade, Faculty of Organizational Sciences, Serbia vojtekn@gmail.com}

Nikola Vojtek is a project manager and business process analyst currently employeed in AirSerbia and has more than 5 years of experience working on different kinds of projects within supply chain and airline industry. He obtained his B.Sc. and M.Sc. in quality management at the Faculty of Organizational Sciences, University of Belgrade.

Currently he is enrolled in Ph.D. studies in the field of System control at the same faculty. So far, he has published papers at domestic and international conferences on various topics regarding business processes, quality and risk management. His focus is

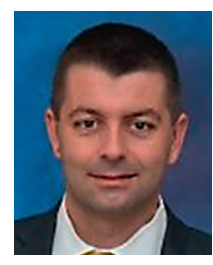
on airline industry. 